\title{
Commentary \\ Circuit lifespan during continuous renal replacement therapy: children and adults are not equal
}

\author{
Zaccaria Ricci ${ }^{1}$, Isabella Guzzo르, Stefano Picca ${ }^{2}$ and Sergio Picardo ${ }^{1}$ \\ ${ }^{1}$ Department of Pediatric Cardiology, Bambino Gesù Hospital, Piazza S. Onofrio 4 00100, Rome, Italy \\ ${ }^{2}$ Department of Nephrology and Urology, Dialysis Unit, Bambino Gesù Hospital, Piazza S. Onofrio 4 00100, Rome, Italy
}

Corresponding author: Zaccaria Ricci, zaccaria.ricci@fastwebnet.it

Published: 16 September 2008

Critical Care 2008, 12:178 (doi:10.1186/cc7000)

This article is online at http://ccforum.com/content/12/5/178

(C) 2008 BioMed Central Ltd

See related research by del Castillo et al., http://ccforum.com/content/12/4/R93

\begin{abstract}
In the field of continuous renal replacement therapy (CRRT), session length, downtime and dose require detailed research, which will provide information important in relation to prescription, anticoagulation and circuit material choice (membrane type and size, vascular access site and size). In particular, it appears that many of the data currently existing in the literature and accepted regarding CRRT prescription and delivery in critically ill adult patients are not strictly applicable to the paediatric setting. Furthermore, many of the available paediatric studies are small, retrospective or underpowered. In paediatric CRRT, epidemiological investigations and prospective trials to investigate practical aspects of extracorporeal therapies are welcome and urgently needed.
\end{abstract}

Del Castillo and coworkers [1] recently reported an interesting prospective study in which they collected information related to circuit life in 122 critically ill children treated with continuous renal replacement therapy (CRRT). The variables significantly associated with prolonged filter life were catheters larger than 6.5 Fr, filters with surface area larger than $0.4 \mathrm{~m}^{2}$, heparin dose greater than $15 \mathrm{UI} / \mathrm{kg}$ per hour and use of haemodiafiltration. In the multivariate logistic regression study, haemodiafiltration, heparin dose greater than $20 \mathrm{UI} / \mathrm{kg}$ per hour, filter surface area of $0.4 \mathrm{~m}^{2}$ or greater, and an initial creatinine of less than $2 \mathrm{mg} / \mathrm{dl}$ were associated with a filter life of more than 24 and 48 hours. Total effluent rate of $35 \mathrm{ml} / \mathrm{kg}$ per hour was related to a filter life of more than 24 hours. No association was found between filter life and patient outcome [1].

Although many of these findings are not unexpected, the report deals with some important issues in paediatric CRRT. First, heparin dose was entered into a multivariate analysis and was confirmed to be a crucial determinant of circuit lifespan. It is unsurprising that a positive correlation between heparin dose and filter life exists. Unfortunately, the authors do not provide information on the patients' anticoagulation parameters or the administration of anticoagulants/antiaggregant drugs, which might have affected blood coagulation. However, no bleeding events related to heparin dose were identified. It has been shown that for every 10 -second increase in activated partial thromboplastin time, the risk for filter coagulation decreases by $25 \%$ but the risk for patient haemorrhage increases by $50 \%$ [2]. Importantly, it remains a therapeutic challenge to use minimal amounts of anticoagulation in order to ensure circuit life and avoid bleeding problems.

In the reported study, longer filter life was identified in association with larger calibre catheters, although this factor did not achieve statistical significance in the multivariate analysis. However, the Pediatric CRRT Registry data clearly revealed a significant association between use of $5 \mathrm{Fr}$ catheters and shorter circuit lifespan $[3,4]$; the investigators showed that 48 -hour survival was $76 \%$ versus $26 \%$ for CRRT using $8 \mathrm{Fr}$ versus $7 \mathrm{Fr}$ access, respectively, and it was less than 10 hours with dual $5 \mathrm{Fr}$ catheters. In the study conducted by del Castillo and coworkers [1], the use of 'oversized' filters in children appeared to overcome the influence of catheter diameter on filter lifespan and was associated with a significantly longer filter survival. According to del Castillo and coworkers [1], larger filters allowed higher blood flows, optimizing shear forces and reducing protein layering, with consequently decreased membrane clotting. This is an interesting finding because it demonstrates for the first time that in children the effect of minimizing membrane saturation by using a large surface may be more important than the increase in inner resistance (usually higher with larger filters). 
Finally, the lack of correlation between filter lifespan and mortality is presented as a side remark by del Castillo and coworkers [1], but in our opinion this raises an important issue. There is growing interest in the impact that the 'downtime' of CRRT (the period during which treatment is not delivered) has on treatment efficiency in adult patients [5-7]. In their randomized controlled trial of continuous venovenous haemofiltration, Ronco and colleagues [5] reported that 425 enrolled patients received at least $85 \%$ of the prescribed dose of haemofiltration (estimated average downtime of 3 to 4 hours). In another study [6], the mean duration of the downtime was 5.4 hours and the prescribed ultrafiltration rate of $35 \mathrm{ml} / \mathrm{kg}$ per hour fell to $23 \mathrm{ml} / \mathrm{kg}$ if downtime was 8 hours/day or more. This value is close to the dose in the control group of the above-mentioned randomized trial (20 ml/kg per day), which had a significantly higher mortality [5]. In the more recent DO-RE-MI (DOse REsponse Multicentre International Collaborative Initiative) trial [7], even higher peaks of downtime duration were reported (up to $28 \%$ ). Taken together, these findings highlight the impact that downtime has on the completion of the prescribed dose of CRRT in critically ill patients. Hence, strict monitoring of downtime in critically ill patients with acute kidney injury has become an emerging issue in adult patients [8].

In children, however, major points of difference must be noted. The use of small solute clearance as a marker of outcome in children has been questioned [9]. In the study of Del Castillo and coworkers, prescription of a total effluent rate greater than $35 \mathrm{ml} / \mathrm{kg}$ per hour was associated with a filter life of more than 24 hours. There are no randomized trials guiding the prescription of CRRT in children. A small solute clearance of $2 \mathrm{l} /$ hour $\times 1.73 \mathrm{~m}^{2}$ has been recommended in paediatric patients [10]. However, one must consider the fact that by applying this recommendation in children weighing less than $30 \mathrm{~kg}$, higher small solute clearances than those described by Ronco and coworkers [5] (namely, $35 \mathrm{ml} / \mathrm{kg}$ per hour) are delivered (Bunchman TE, personal communication). This would render the above recommended prescription in children very close to the 'high volume haemofiltration' administered to adults [11], but maybe CRRT dose is not the most important difference between adults and children. Rather, practical clinical problems have significant impact in pediatric CRRT, such as the frequent interruption of total parenteral nutrition due to repeated interruptions to the CRRT treatment of an anuric child that may induce severe undernutrition and increased catabolism. The repeated blood loss due to oversized circuits may cause anaemia and increased need for transfusion. In our opinion, the solution of such problems is more likely to contribute to a positive outcome (and would deserve dedicated studies) than the struggle to achieve a ill-defined paediatric dialysis dose.

In conclusion, increased awareness of the importance of CRRT session length, downtime and dose are progressively leading to more detailed research in the field of anticoagula- tion and vascular access. In the paediatric setting, epidemiological studies - such as that reported by del Castillo and coworkers [1] - and prospective trials comparing different extracorporeal circuit management strategies and providing recommendations to operators in the field are welcome and urgently needed.

\section{Competing interests}

The authors declare they have no competing interests.

\section{References}

1. Del Castillo J, López-Herce J, Cidoncha E, Urbano J, Mencía S, Santiago MJ, Bellón JM: Circuit life span in critically ill children on continuous renal replacement treatment: a prospective observational evaluation study. Crit Care 2008, 12:R93.

2. van de Wetering J, Westendorp RG, van der Hoeven JG, Stolk B, Feuth JD, Chang PC: Heparin use in continuous renal replacement procedures: the struggle between filter coagulation and patient hemorrhage. J Am Soc Nephrol 1996, 7:145-150.

3. Hackbarth R, Bunchman TE, Chua AN, Somers MJ, Baum M, Symons JM, Brophy PD, Blowey D, Fortenberry JD, Chand D, Flores FX, Alexander SR, Mahan JD, McBryde KD, Benfield MR, Goldstein SL: The effect of vascular access location and size on circuit survival in pediatric continuous renal replacement therapy: a report from the PPCRRT registry. Int J Artif Organs 2007, 30:1116-1121.

4. Goldstein SL, Hackbarth R, Bunchman TE, Blowey D, Brophy PD; Prospective Pediatric Crrt Registry Group Houston: Evaluation of the PRISMA M10 circuit in critically ill infants with acute kidney injury: a report from the Prospective Pediatric CRRT Registry Group. Int J Artif Organs 2006, 29:1105-1108.

5. Ronco C, Bellomo R, Homel P, Brendolan A, Dan M, Piccinni P, La Greca G: Effects of different doses in continuous venovenous haemofiltration on outcomes of acute renal failure: a prospective randomised trial. Lancet 2000, 356:26-30.

6. Uchino S, Fealy N, Baldwin I, Morimatsu H, Bellomo R: Continuous is not continuous: the incidence and impact of circuit 'down-time' on uraemic control during continuous venovenous haemofiltration. Intensive Care Med 2003, 29:575-578.

7. Monti G, Herrera M, Kindgen-Milles D, Marinho A, Cruz D, Mariano F, Gigliola G, Moretti E, Alessandri E, Robert R, Ronco C; Dose Response Multicentre International Collaborative Initiative Scientific Committee: The DOse REsponse Multicentre International Collaborative Initiative (DO-RE-MI). Contrib Nephrol 2007, 156:434-443.

8. Ricci Z, Salvatori G, Bonello M, Pisitkun T, Bolgan I, D'Amico G, Dan M, Piccinni $P$, Ronco $C$ : In vivo validation of the adequacy calculator for continuous renal replacement therapies. Crit Care 2005, 9:R266-R273.

9. Goldstein SL: Adequacy of dialysis in children: does small solute clearance really matter? Pediatr Nephrol 2004, 19:1-5.

10. PCRRT homepage [www.pcrrt.com].

11. Venkataraman R, Subramanian S, Kellum JA: Clinical review: Extracorporeal blood purification in severe sepsis. Crit Care 2003, 7:139-145. 